\title{
Design for Additive Manufacturing of a Topology Optimized Brake Caliper Through CAD-Platform-Based Systematic Approach
}

\author{
Enrico Dalpadulo, Fabio Pini ${ }^{(凶)}$, and Francesco Leali \\ "Enzo Ferrari" Department of Engineering, University of Modena and Reggio Emilia, \\ Via Vivarelli 10/1, 41125 Modena, Italy \\ \{enrico.dalpadulo, fabio.pini\}@unimore.it
}

\begin{abstract}
To implement the CAD platform-based approach of Design for Additive Manufacturing (DfAM) and validate it in a real case, an entire design optimization process of a Formula SAE front brake caliper has been performed, to be printed by Powder Bed Fusion (PBF) process. The DfAM consists in the use of a Ti6Al4V titanium alloy to better resist at high temperatures and a topology optimized shape allowed by the technology to save weight despite the density increase. Structural and thermal behavior has been discussed. DfAM process-specific techniques have been implemented for internal geometrical features and optimized shapes. The design for additive workflow is presented and finally the exploited design approach based on a CAD platform is synthesized.
\end{abstract}

Keywords: DfAM - Topology optimization - CAD platform · Brake caliper · Automotive

\section{Introduction}

Since Additive Manufacturing (AM) implementation is giving great potentials in many industrial settings, especially those focused on high performance components, DfAM methodologies study is becoming fundamental [1]. As shown in a previous work by the authors [2], the workflow for the development of optimized components to be produced by AM is not always effective. A general framework consisting of the tasks to be performed from concept definition to end-use functional parts has been defined (Fig. 1).

The main operations that make up the workflow are summarized below. Product Planning is the initial phase. At this stage, analyses on parts and assemblies together with objectives and constraints definition are carried out to collect all the input Product Data and define the Requirement List.

The Design phase is an iterative refinement of the models in order to optimize the product. The Industrialization phase is the step required to make reliable part production and optimize the process. Finally, Production covers part printing process, with the related post-processing and control operations. The implementation of integrated CADbased platforms as backbone tool to speed up the workflow and increase its effectiveness 


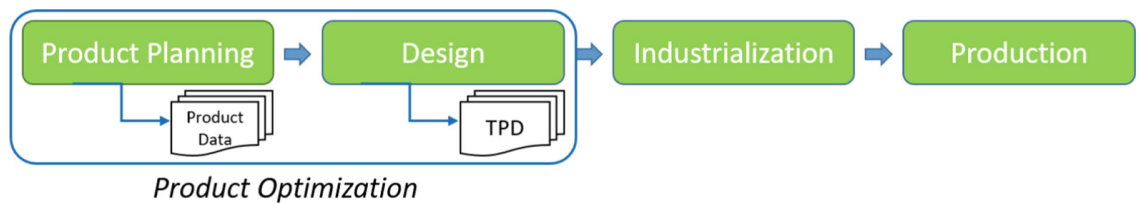

Fig. 1. Design for Additive Manufacturing workflow [2].

had been discussed by the authors [2]. The presented work aims to describe in detail the methodologic approach focused on the Design phase (Product Optimization) based on Topology Optimization. A racing automotive brake caliper has been re-designed to be produced by Selective Laser Melting (SLM) AM, with performance improvement objectives, through the application of the CAD platform-based approach. The iterative design refinement required to obtain final models and Technical Product Documentation (TPD) is described on a real-case application and the DfAM approach is analyzed.

\section{Method}

As depicted in Fig. 2, the Design phase relies on a sequence of tasks, that are summarized below. CAD modelling of Design Space (DS) and Non-Design Space (NDS) are mandatory to prepare the geometry considering the design constraints.

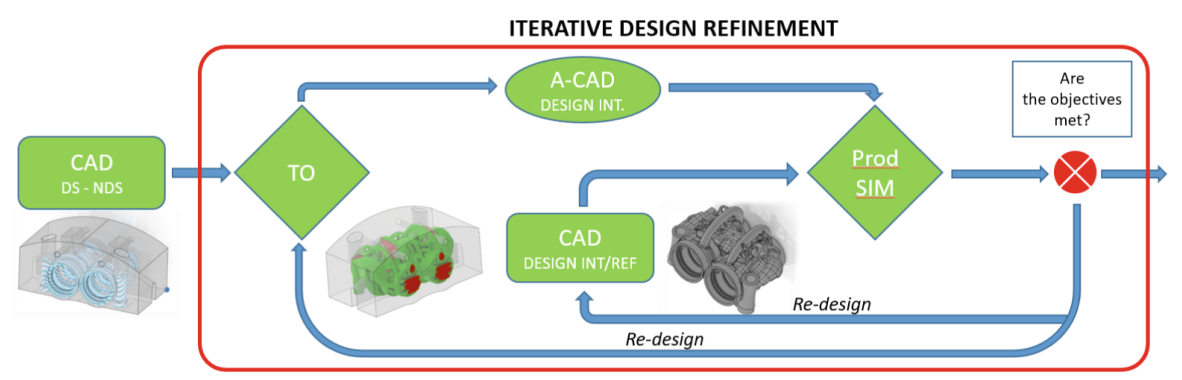

Fig. 2. Design phase.

Topology Optimization (TO) is the task to compute part shape according to algorithm settings of target and constraints. CAD design interpretation/refinement is required to obtain the optimized part model and both automatic tools (A-CAD) or manual geometry reconstruction (CAD) can be used. Product Simulation (ProdSIM) is the validation task of the optimized parts with respect to the design objectives and constraints. Re-design loops are required for design optimization.

\section{Case Study}

Components of racing cars are usually subjected to combined stressing factors and in particular braking systems can have issues in use, as they have to work with intense 
loads at high temperatures [3]. A commercial Formula SAE brake caliper, originally made by CNC milling of Ergal 7075-T6 aluminum alloy, reached temperatures close to $300{ }^{\circ} \mathrm{C}$ with problems of strength and deformation, so it has been re-designed to be printed by SLM process. Sergent et al. analyses [4] show critical conditions for a working brake caliper from a structural point of view and how Topology Optimization let its performance improvements. Travi Farias et al. work [5] shows how its thermal management is fundamental, since at high temperatures materials mechanical properties decline. Moreover, the study states that AM enables the construction of complex geometries that can increase model surface/volume ratio and facilitate heat dissipation. Bugatti's full developed case [6] demonstrates with experimental testing how titanium alloys use is feasible and leads to performance improvements. Nevertheless, none of these cases is based on an integrated design approach, whose possible potentials have been discussed by the authors [2]. Referring to the workflow depicted in Fig. 1, the Product Planning and Design tasks are now described. All the tasks are performed on the Dassault Systèmes 3DExperience CAD platform [7] for integrated product-process design.

\subsection{Product Planning}

The analysis of the commercial component is the starting point of DfAM with the aim to define the design features that provide the same working behavior. In particular, that concerns mostly the fluid-dynamic of oil channels. In addition, a make/buy decision step leads to keep standard and commercial elements of the original part, whereas the body and pistons are re-designed. Since original 2D drawing is not available, functional features have been measured by metrology equipment to define the coupling tolerances. Data about mechanical and thermal loads acting on the part have been collected via experimental measurements and analytical models from the vehicle dynamics. Maximum pressure on the oil circuit is 100 bar and tangential load for maximum brake torque at the disc brake is $14 \mathrm{kN}$. Temperatures reach on average about $200{ }^{\circ} \mathrm{C}$ with maximum peaks close to $300{ }^{\circ} \mathrm{C}$. An analysis on the assembly of the front wheel group has been done in order to define physical design constraints related to part fitting, coupling and working. Based on that data-set, FEA of the original caliper returns the structural targets for the project, such as improvement of stiffness at high temperature and weight reduction. A fundamental step is material selection, according to datasheets related to SLM. Since mechanical properties of 7075-T6 alloy suffer of significant drop at high temperature, Ti6Al4V titanium alloy is selected. According to literature data, compared to 7075-T6 alloy, it presents, at working temperature, about 11\% higher Young's-modulus/density ratio and even $45 \%$ higher yield-stress/density ratio. Moreover, manufacturing analysis, with machining and specific heat and surface treatments is required. Product Data are collected in the Requirement List. The DfAM goals consist in the use of Ti6Al4V to better resist at high temperatures and a topology optimized shape to save weight. An opened and branched geometry can also increase surface/volume ratio with benefits for thermal management in terms of heat dissipation. 


\subsection{Design}

Initial step of the Design phase is the DS modeling. It starts from the input data of part and assembly analysis in order to define the maximum volume available for the TO computation. Most functional elements should be removed whereas features for part connections and main couplings must be kept (pistons, brake pads and pins housings, bolt holes, caliper caps) in order to constrain the region. Wheel rim radius, encumbrance of wheel knuckle and brake disk or parts assembly trajectories are also required. NDS volumes must be defined in order to insert regions to keep material, such as bolts holes or internal features.

The second step is the setup of FE model in order to run optimizations and analyses. Hinge restraints are applied for the screws. Maximum $14 \mathrm{kN}$ tangential load (due to braking torque) is applied on a node put on the disk brake midplane, connected to contact surfaces (RBE3) of braking pads. Maximum 100 bar oil pressure is applied on internal surfaces of pistons housings and equivalent calculated reacting forces of $9.8 \mathrm{kN}$ are applied on the thread regions of the caliper caps. Material is created using parameters for build direction (due to AM alloy anisotropy [8]) in favor of security. Discretization of the design space is made by a $1.5 \mathrm{~mm}$ tetrahedron (TL4) mesh and refinements. A preliminary static analysis on the design space is run to validate the model setup and check its stiffness (ideal maximum value). TO is setup with target mass reduction and minimization of compliance.

A conceptual iterative design exploration with a symmetry constraint study and a computational refinement is performed. That geometry makes the right and left parts become the same and reduces the modeling to half-body, with potential benefits of design and production time and costs. The results are used to create solid models through improved smoothing conceptual shape generation. These see directly ProdSIM by FEA, showing that an asymmetrical design plain brings better performance in terms of maximum displacement. Figure 3 shows TO results $\mathrm{C} 1$ and $\mathrm{C} 2$.
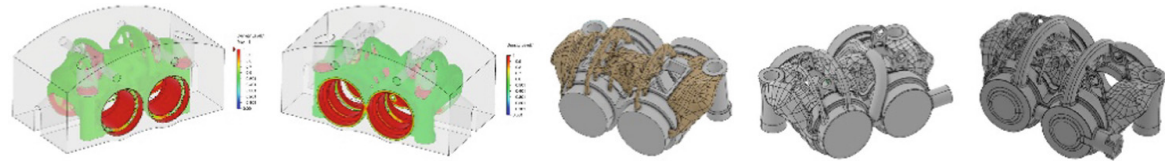

Fig. 3. From left to right, conceptual results (C1, C2) and designs (V1, V2, V3).

Once the TO is finished, an embodiment iterative design starts to improve part shape. The Design Interpretation occurs, modeling the functional geometry with surface design and the branched shape with free-shape design. Moreover, oil channels are introduced and used to contribute to part stiffness working on their shape and position. ProdSIM by FEA is necessary to predict part deformation and stress. Last two refinement cycles involve the detailed design of each part housings (gaskets, o-rings, valves, pins) and the implementation of DfAM guidelines for internal features (self-supporting cross-sections of channels) and the branched shapes (thickness, supporting angles), according to part orientation planned for construction. After validation, results of manufacturing analysis are used to create the raw part model and the final drawings (TPD). 


\section{Results and Discussion}

For static load validation, yield stress at $220{ }^{\circ} \mathrm{C}$ is considered, with value for build direction $(\mathrm{Z})$ and an additional safety factor 1.2 (racing application), so permissible stress of $560 \mathrm{MPa}$ is calculated. Figure 4 shows results. Moreover, remark on fatigue life and proper processing/treatments on stressed areas is necessary [9].
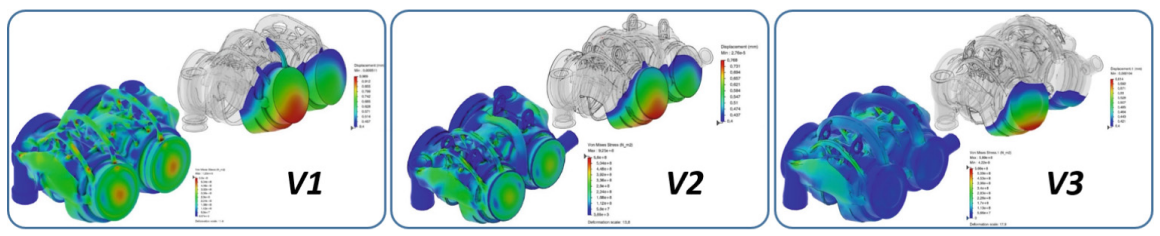

Fig. 4. Displacement and stress of V1, V2 and V3.

As reported in Table 1, maximum displacement at $220^{\circ} \mathrm{C}$ is $0.675 \mathrm{~mm}$ for the original caliper and $0.614 \mathrm{~mm}$ for the final design of the optimized one (9\% reduction) while the body weight goes from $248 \mathrm{~g}$ to $184 \mathrm{~g}$ (25,8\% saving). Moreover, an analytical thermal study of a braking cycle by Matlab code shows a $20^{\circ} \mathrm{C}$ decrease of working temperatures for the final design. One last note is that titanium has worst tribological characteristics (low wear resistance and high size tendency) and thus surface treatment chemical nickel-plating (Niplate) for pistons housings has been defined. Cold and hot tolerances for couplings are re-calculated.

Table 1. Comparison between designs.

\begin{tabular}{l|l|l|l}
\hline & Original & V2 & V3 \\
\hline Weight [g] & 248 & 176 & 184 \\
\hline Displacement [mm] @ 220 ${ }^{\circ} \mathrm{C}$ & 0.675 & 0.768 & 0.614 \\
\hline Deformation \% @ 220 ${ }^{\circ} \mathrm{C}$ & - & +13.78 & -9.03 \\
\hline Displacement [mm] @ 20 ${ }^{\circ} \mathrm{C}$ & 0.555 & 0.694 & 0.551 \\
\hline Deformation \% @ 20 ${ }^{\circ} \mathrm{C}$ & - & +25.05 & -0.72 \\
\hline
\end{tabular}

The iterative design refinement is now synthesized. Loops for product optimization, each of them performed in the integrated CAD platform, can be outlined at different levels. First loop includes Topology Optimization, A-CAD and Product Simulation and produces conceptual solutions $(\mathrm{C} 1, \mathrm{C} 2)$. Automatic tools for design interpretation are used and loops are made fast thanks to the integrated platform. Second loop includes CAD and Product Simulation and lets the development of embodiment solutions (V1) or definitive ones (V2, V3) adding elements of the detail design. Design requires manual (time-consuming) geometry interpretation only for first iteration, whereas re-designs are extremely facilitated by the integrated environment for the subsequent ones. 


\section{References}

1. Kumke, M., Watschke, H., Vietor, T.: A new methodological framework for design for additive manufacturing. Virtual Phys. Prototyping 11(1), 3-19 (2016)

2. Dalpadulo, E., Pini, F., Leali, F.: Assessment of design for additive manufacturing based on CAD platforms. design tools and methods in industrial engineering. In: Proceedings of ADM 2019, pp. 970-981 (2020)

3. Limpert, R.: Brake Design and Safety, S.A.E. International, U.S.A. (1999)

4. Sergent, N., Tirovic, M., Voveris, J.: Design optimization of an opposed piston brake caliper. Eng. Optim. 14(11), 1520-1537 (2014)

5. Travi Farias, L., Schommer, A., Ziegler Haselein, B., Neumaier, G., Costa de Oliveira, L., Soliman, P., Walter, R.: Design of a Brake Caliper using Topology Optimization Integrated with Direct Metal Laser Sintering. S.A.E. International (2015)

6. Wischeropp, T.M., Hoch, H., Beckmann, F., Emmelmann, C.: Opportunities for braking technology due to additive manufacturing through the example of a Bugatti brake caliper. In: XXXVII. Internationales $\mu$-Symposium 2018 Bremsen-Fachtagung, pp. 181-193 (2019)

7. Dassault Systèmes. https://www.3ds.com/about-3ds/3dexperience-platform/. Accessed 01 2020

8. Simonelli, M., Tse, Y.Y., Tuck, C.: Effect of the build orientation on the mechanical properties and fracture modes of SLM Ti6Al4V. Mater. Sci. Eng. 616, 1-11 (2014)

9. Denti, L., Bassoli, E., Gatto, A., Santecchia, E., Mengucci, P.: Fatigue life and microstructure of additive manufactured Ti6Al4V after different finishing processes. Mater. Sci. Eng. 755, $1-9$ (2019)

Open Access This chapter is licensed under the terms of the Creative Commons Attribution 4.0 International License (http://creativecommons.org/licenses/by/4.0/), which permits use, sharing, adaptation, distribution and reproduction in any medium or format, as long as you give appropriate credit to the original author(s) and the source, provide a link to the Creative Commons license and indicate if changes were made.

The images or other third party material in this chapter are included in the chapter's Creative Commons license, unless indicated otherwise in a credit line to the material. If material is not included in the chapter's Creative Commons license and your intended use is not permitted by statutory regulation or exceeds the permitted use, you will need to obtain permission directly from the copyright holder.

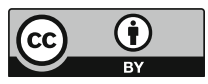

